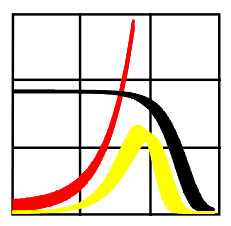

Max-Planck-Institut für demografische Forschung

Max Planck Institute for Demographic Research

Doberaner Strasse 114 - D-18057 Rostock · GERMANY

Tel +49 (0) 3812081 - 0; Fax +49 (0) 3812081 - 202;

http://www.demogr.mpg.de

MPIDR WORKING PAPER WP 1999-009

JULY 1999

\title{
Male-female Differences in Mortality in the Developed World
}

Arjan Gjonça (agjonca@demogr.mpg.de)

Cecilia Tomassini (tomassini@demogr.mpg.de)

James W. Vaupel (jwv@demogr.mpg.de)

C) Copyright is held by the authors.

Working papers of the Max Planck Institute for Demographic Research receive only limited review. Views or opinions expressed in working papers are attributable to the authors and do not necessarily reflect those of the Institute. 


\title{
Male-female differences in mortality in the developed world
}

\author{
Dr. Arjan Gjonça \\ Post-doctoral Fellow, Max Plank Institute for Demographic Research, Rostock. \\ Dr. Cecilia Tomassini \\ Post-doctoral Fellow, Max Plank Institute for Demographic Research, Rostock. \\ Prof. James W. Vaupel \\ Director, Max Plank Institute for Demographic Research, Rostock \\ http://www.demogr.mpg.de
}

\section{Introduction}

Women live longer than men. Indeed, in developed countries today women live 6 years longer than men on average. This difference varies from country to country. In 1996 France had the largest gap in the developed world, with a male-female difference in life expectancy at birth $^{1}$ of 7.8 years. The United Kingdom had one of the lowest gender differences, with a gap of only 4.9 years. Mortality gaps are also found in the developing world, although they are of a different magnitude there.

How can this difference be explained? Why should there be this sex discrepancy in the majority of the world's countries? Why are there great differences among countries, such as that between France and the UK? And more generally, why do women live longer than men? It is impossible to cover all the research that demographers and other researchers have conducted on the question. Here we seek to sketch a general picture of the male-female mortality disparity, both at present and from an historical perspective, and to outline the main reasons behind it.

Table 1. Selected developed countries by order of male-female difference (in years) of life expectancy at birth 1980-1996 (about here).

\section{Recent trends in male-female differences in mortality}

Men have a lower life expectancy at birth than women in all industrialised countries. The magnitude of this sex difference varies considerably from one country to another and from one year to the next. In 1970 the countries with the highest sex differences were Finland and United States, with differences of 8.5 and 7.6 years, respectively. Greece and Ireland had the lowest differences, with 3.7 and 4.7 years, respectively. By 1996 this order had changed. Now France and Finland had the highest values at 7.8 and 7.5 years, while United Kingdom and Sweden had the lowest gap, with 4.9 and 5.0 years (Table 1$)$.

A closer look at the sex difference in mortality by age shows that females have lower mortality at all ages (Figure 1). Despite the fact that more boys are born than girls (on average, 105 boys are born for every 100 girls) the number of living males decreases rapidly. Infant and childhood mortality is higher for boys than for girls and these

\footnotetext{
${ }^{1}$ Life expectancy at birth is the average number of years a newly born baby is expected to live if death rates remain at current levels. It is widely used in various disciplines as a general indicator of mortality.
} 
higher death rates ${ }^{2}$ for males continue throughout their entire life span. By age 25 the number of women alive in a cohort exceeds the number of men, and this continues to be the case until the cohort is extinct. This sex difference is most significant at old ages. In 1996, women aged 85 and over outnumbered men in the United States by a factor of 1.8, in Japan (1995) by a factor of 2.3, in France (1996) by a factor of 2.7, and in Great Britain (1995) by a factor of 2.9.

There are still large differences among industrialised countries regarding the age pattern of male versus female mortality. Central European countries such as Switzerland, Austria, and Germany have similar age-specific patterns of sex differences in mortality, exemplified by the curve for Germany in Figure 1. Countries such as Denmark, Sweden, the United States, and the United Kingdom show a different pattern. Eastern European countries such as Poland, Hungary, and the Czech Republic are known to have higher excess mortality for males over the age of 20, which has become especially prominent in the last decade. Another pattern of sex disparity by age can be seen in France, where male-female differences ${ }^{3}$ after age 30 are higher than in most other developed countries today.

Figure 1. Sex differences in mortality expressed as the ratio of male/female death rates (about here).

Figure 1 shows the age-sex mortality patterns of a few selected countries. It is clear that these countries exhibit significant differences in their levels of excess mortality after age 30. Compared to Denmark, the sex differences in mortality in France almost double at adult ages. This is a result of relatively low male adult mortality in Denmark and high female mortality at the same ages. In France we have the opposite state of affairs - relatively high male adult mortality and low female mortality. In Eastern Europe the sex difference appears to have widened as a result of increased adult male mortality in the last decade. This increase is due mainly to the high death rates from accidents at young ages, and to very high death rates from cardiovascular diseases in late adulthood. The countries of Central Europe, represented by Germany in the graph, have a mortality pattern of sex differences which runs between that of France and Eastern Europe on one hand and Denmark on the other. These countries have relatively low adult mortality for both sexes.

Why does France behave differently from other Western European countries? A careful observation of the specific causes of mortality shows that the high adult mortality among males in France is due mostly to high rates of cancer, particularly lung cancer. In this respect France is similar to Eastern European countries. The opposite is true when cardiovascular mortality is considered. France has one of the lowest death rates from cardiovascular diseases for men as well as for women. It is interesting to note that France has one of the lowest rates of female mortality from cancer in Europe, again, particularly lung cancer (Haut Comité de la Santé Publique, 1994). This fact suggests that the behaviour of French men and women differs with regard to risk factors, particularly smoking.

\footnotetext{
${ }^{2}$ Death rates (or mortality rates) are calculated for the entire population, but also for each age group. They are calculated as the ratio of the number of deaths within a period (usually a year) for a particular age and the population at risk - the number of people at a particular age.

${ }^{3}$ Male female differences are analysed through the ratios of male to female death rates for each age.
} 


\section{Historical perspective on sex-related differences in mortality}

Today, women have a mortality advantage at almost all ages in all developed societies. But this has not always been the case. Paleo-demographers are now establishing evidence that there may have been no life expectancy difference between males and females prior to the development of agriculture. Following the development of agriculture, females may have then suffered higher mortality than males. It has not yet been established whether this female disadvantage was brought about by a heavy work burden, high fertility, the microbiological environment or other factors (Boldster and Paine, 1995). The oldest records on mortality are from England and Wales and from Sweden. The data reconstructed for England and Wales show that from the early $17^{\text {th }}$ to the $20^{\text {th }}$ century male and female mortality differed only little. In general males had a slight advantage in the $17^{\text {th }}$ and $18^{\text {th }}$ centuries, but females enjoyed lower mortality during some periods. The male-female difference varied from 0 to 2 years of life expectancy at birth. For example, between 1625 and 1649 life expectancy at birth in England and Wales was 38.7 years for males and 37.6 for females; from 1725 to 1749 it was of 37.4 years for females, while male life expectancy at birth was lower, at 35.8 years. In a later period this pattern changes once again, with males having a slight advantage. From 1775 to 1799 men were living up to 40.8 and women to 39.5 years (Wrigley et al. 1998).

Figure 2. Lexis maps for the sex ratios of death rates for Denmark and France (about here).

The development of a significant male-female disparity in mortality did not take place until this century. France and Denmark, whose mortality histories have been well reconstructed, illustrate this development. Figure 2 shows the ratio of male/female death rates at each age from 1889 to 1996. A ratio of more than one (shown in red) indicates higher male mortality. For example, a clear male disadvantage can be observed for the ages 20 to 50 in France during the years of the two world wars. This is indicated in the map by two large red rectangles. Another clear case of male disadvantage in mortality is between ages 18 and 25 for both France and Denmark, from 1950 onwards. The high male mortality resulting from accidents creates a higher ratio between the two sexes.

The two maps in figure 2 clearly indicate that the male disadvantage started much earlier in France than in Denmark, especially at reproductive ages. This is mainly due to the fact that France underwent a fertility transition, i.e., a reduction in the female death rates at reproductive ages, at an earlier stage than other European countries. Denmark, like most other European countries, had high female mortality at reproductive ages, which can be attributed to maternal mortality. Both countries exhibit a female disadvantage in early life between the ages of 5 and 15 . This disadvantage, which was found in most European populations, was present from 1800 until it disappeared in the 1920s and 1930s. Data on causes of death show that infectious and parasitic diseases account for very high female mortality at these ages, tuberculosis being the main killer. The frailty of young girls from 5 to 15 with regard to tuberculosis has been attributed to hereditary factors, as well as living, working and 
housing conditions. This excess mortality for girls was the result of the sexual discrimination that characterised Western societies in the 19th century. Various factors played a role here, such as nutrition, housing and hygiene, access to education and medical assistance, and working conditions (Tabutin and Willems 1996).

The world's population has experienced a rapid improvement in mortality in the second half of this century. Life expectancy has increased dramatically, particularly in the past thirty years. This rapid improvement in the developed world was accompanied by an increase in the gap between male and female survival. This widening sex difference is due mainly to the higher pace of improvement for females rather than to a decrease in life expectancy for males. This increased disparity is obvious in both France and Denmark, where male mortality is twice as high as that of females for some age groups. Figures 1 and 2 both clearly show two main peaks of this disparity: the first at young ages (20-35), which is the result of increased death rates from accidents and violence among males, and the second in late adulthood and at the beginning of old age, where the cardiovascular and cancer rates are much higher for males than females. The gaps between the two sexes for these major causes of death have been increasing in most of the developed countries since World War II.

A distinctive feature of France shown in both Figures 1 and 2 is the very high disparity between the two sexes for ages 35-55 from the mid-1960s to the present day. The growth of excess male mortality in France at ages 35-55 can be largely attributed to the fact that mortality improvements were much more rapid for women than for men. The high prevalence of smoking among men is also a factor. Mortality from combined cancers decreased for women and increased for men during this period. Cardiovascular death rates decreased for both sexes, but far more rapidly for women than for men (Vallin, 1995).

It is interesting to note that the second peak of the sex disparity - at late adulthood and the beginning of old age - has been shifting with time. While in 1960 the highest point for these ages was around 55-65, in 1996 it was around the ages 65 to 75 for Denmark. This is also true for France, but the shift occurred over a longer period. This shift of the peak clearly shows the improvement in mortality at old ages in the last three decades.

\section{Biology versus behaviour and socio-economic factors}

Why have women been living longer than men in the $20^{\text {th }}$ century? Is it because of natural biological differences between the two sexes, because nature endows men at birth with smaller health reserves? Or is it due to the differentiation that comes about through the different roles of men and women in society? We think that both these factors are seen as contributing to this disparity in mortality.

In his classic work Madigan hypothesised that fundamental biological differences account for male-female differences in the 20th century (Madigan, 1957). He concluded that socio-cultural factors had made only a small contribution to the growing male excess in mortality and that nature itself was by far the most important force shaping the survival rates of men and women. There are several studies 
suggesting that males have higher rates of fetal mortality. Waldron (1995) claims that the sex differences in ischaemic heart disease mortality are the main contributor to the overall mortality difference in the industrialised world. She analyses different types of biological factors and concludes that women's sex hormones reduce the risk of ischaemic heart disease, in part by the favourable effects they have on serum lipids. In contrast, men's higher testosterone levels have unfavourable effects on serum lipids. She suggests another biological factor as a cause for some of the difference: men's tendency to accumulate abdominal body fat appears to contribute to their unfavourable serum lipid levels and consequently to their higher ischaemic heart disease mortality.

But if the reason for differences in mortality between the two sexes is predominantly biological, why then two countries such as France and the UK have different patterns. Clearly, biological factors can explain only part of the variation in mortality between the two sexes. Social, environmental and behavioural factors must also play a role.

Behavioural factors, such as smoking, diet, as well as medical care, account for some of the male-female differences in mortality at adult ages. The diseases that contribute most to the widening mortality gap between the two sexes, such as cardiovascular diseases and lung cancer, are linked to cigarette consumption. It is known that, in almost all populations studied, more men than women smoke and that, among smokers, men tend to have more hazardous smoking habits than women. Evidence from various studies in different countries suggests that from the 1950s to the present smoking has been a major contributor to sex differences in cardiovascular mortality and, consequently, to overall mortality differences between the sexes. Independent studies suggest that about $50 \%$ of sex differences in ischaemic heart disease mortality are attributable to differences in smoking behaviour (Waldron, 1995).

Other studies have suggested that the different social roles of the two sexes affect their respective mortality rates, with particular emphasis on the fact that males tend to be employed in more dangerous, harmful, stressful, or difficult occupations than women. This hypothesis can explain some of the variation in mortality between the two sexes in the 1920s and 1930s. Recent efforts to explain sex differences in mortality on the basis of socio-economic differences conclude that socio-occupational factors have not played a central role in promoting excess male mortality in the late twenty century (Vallin, 1995).

In conclusion, a very wide and extensive range of literature attributes the sex mortality differences in the second half of this century primarily to behavioural factors such as smoking. Changes in the social roles played by the two sexes are shaping these behavioural factors. As social and behavioural differences between men and women diminish in the future, the male-female mortality gap may narrow. 


\section{References}

1. Boldsen J.L. and Paine R.R. The evolution of human longevity from Mosolothic to the Middle Ages: An analysis based on skeletal data. In: Exceptional Longevity: from prehistory to the present, edited by Jeune, B. and Vaupel, J.W. Odense, Odense University Press, 1995

2. Haut Comité de la Santé Publique, «La santé en France », la Documentation Française, 1994 - Rapport général et Annexe : travaux des groupes thématiques

3. Madigan FC, Are sex mortality differentials biologically caused? Millbank Memorial Fund Quarterly, 1957: 25 p. 202-223

4. Tabutin D; Willems M. Excess mortality of girls up to 1940: a good example of sexual inequalities in Western history. [La surmortalite des filles jusqu'en 1940: un bel

exemple des inegalites sexuelles dans l'histoire occidentale.] In: Sante et mortalite des enfants en Europe: inegalites sociales d'hier et d'aujourd'hui, edited by Godelieve Masuy-Stroobant, Catherine Gourbin, and Pierre Buekens. Louvain-la-Neuve, Belgium, Academia-Bruylant, 1996. p. 129-77.

5. Vallin J. Can sex differentials in mortality be explained by socio-economic mortality differentials? In: Adult mortality in developed countries: from description to explanation, edited by Alan D. Lopez, Graziella Caselli, and Tapani Valkonen. Oxford, England, Clarendon Press, 1995. p. 179-200.

6. Waldron I. Contributions of biological and behavioural factors to changing sex differences in ischaemic heart disease mortality. In: Adult mortality in developed countries: from description to explanation, edited by Alan D. Lopez, Graziella Caselli, and Tapani Valkonen. Oxford, England, Clarendon Press, 1995. p. 161-78.

7. Wrigley EA; Davies RS; Oeppen JE; Schofield RS. English population history from family reconstitution, 1580-1837. New York, New York, Cambridge University Press, 1997. 
Table 1. Selected developed countries by order of male-female difference (in years) of life expectancy at birth in 1980 and 1996.

\begin{tabular}{lllll}
\hline & 1996 & & 1980 & \\
\hline & $\begin{array}{l}\text { Female-Male } \\
\text { Difference }\end{array}$ & Ranking & $\begin{array}{l}\text { Female-Male } \\
\text { Difference }\end{array}$ & Ranking \\
\hline United Kingdom & 4.9 & 1 & 6.0 & 4 \\
Sweden & 5.0 & 2 & 6.0 & 4 \\
Denmark & 5.2 & 3 & 6.1 & 6 \\
Greece & 5.3 & 4 & 4.6 & 1 \\
Ireland & 5.3 & 5 & 5.5 & 3 \\
Netherlands & 5.6 & 6 & 6.6 & 8 \\
United States & 6.0 & 7 & 7.4 & 12 \\
Austria & 6.3 & 8 & 7.1 & 11 \\
Italy & 6.4 & 9 & 6.8 & 10 \\
Japan & 6.5 & 10 & 5.3 & 2 \\
FR of Germany & 6.5 & 11 & 6.8 & 7 \\
Spain & 7.2 & 12 & 6.1 & 14 \\
Finland & 7.5 & 13 & 9.1 & 13 \\
France & 7.8 & 14 & 8.2 & \\
\hline Mean & 6.2 & & 6.6 & 1.156 \\
Standard Deviation & 0.987 & & 4.5 & \\
Range & 3.0 & & & \\
\hline
\end{tabular}

Source: Eurostat, Demographic statistics, 1997

Figure 1. Sex mortality differences expressed as the ratio of male/female death rates

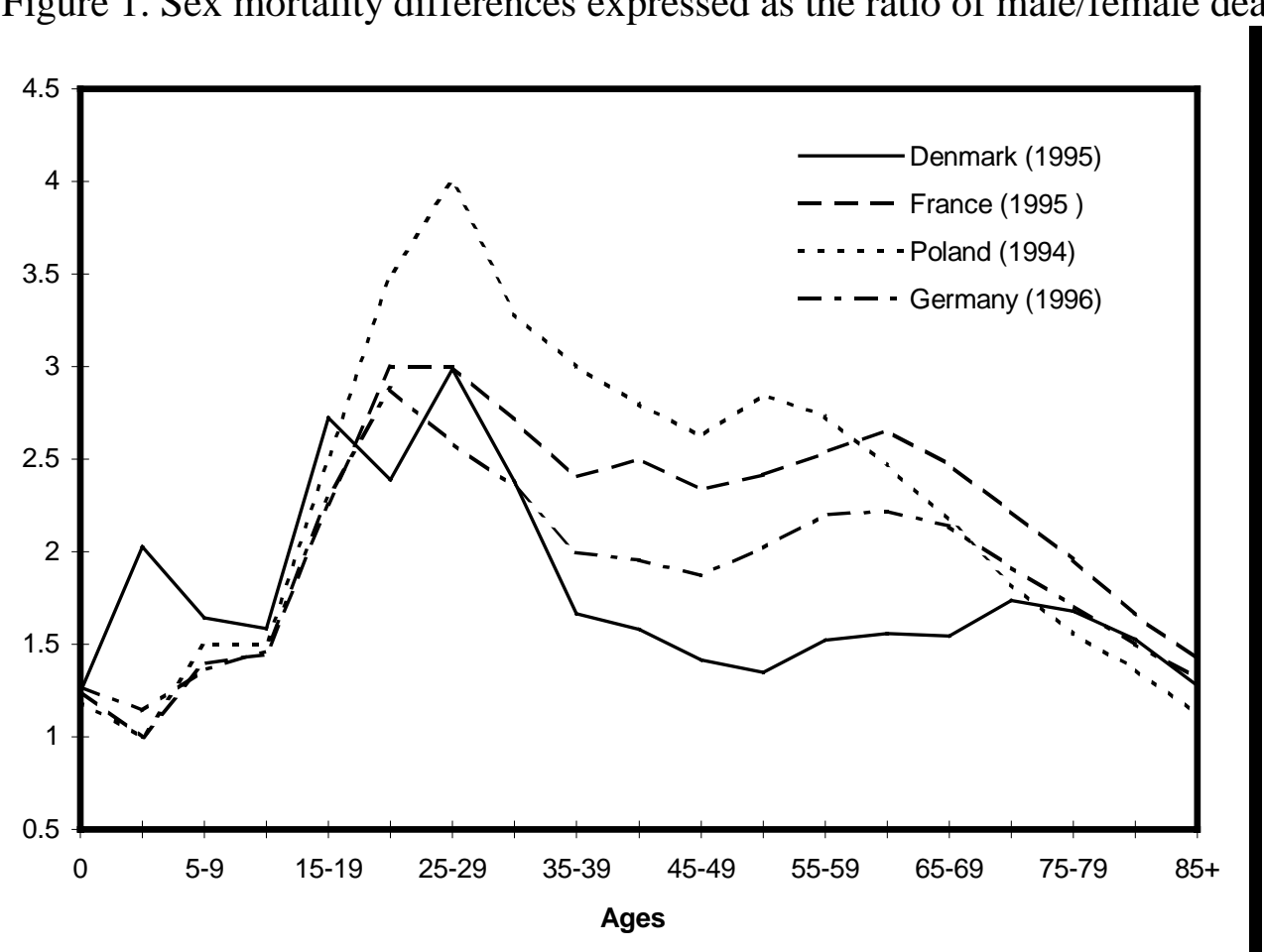

Source: Nations Unies 1998, Annuarie Demographique - 1996, New York. 
Figure 2. Lexis maps for the sex ratios of death rates for Denmark and France.

a. France

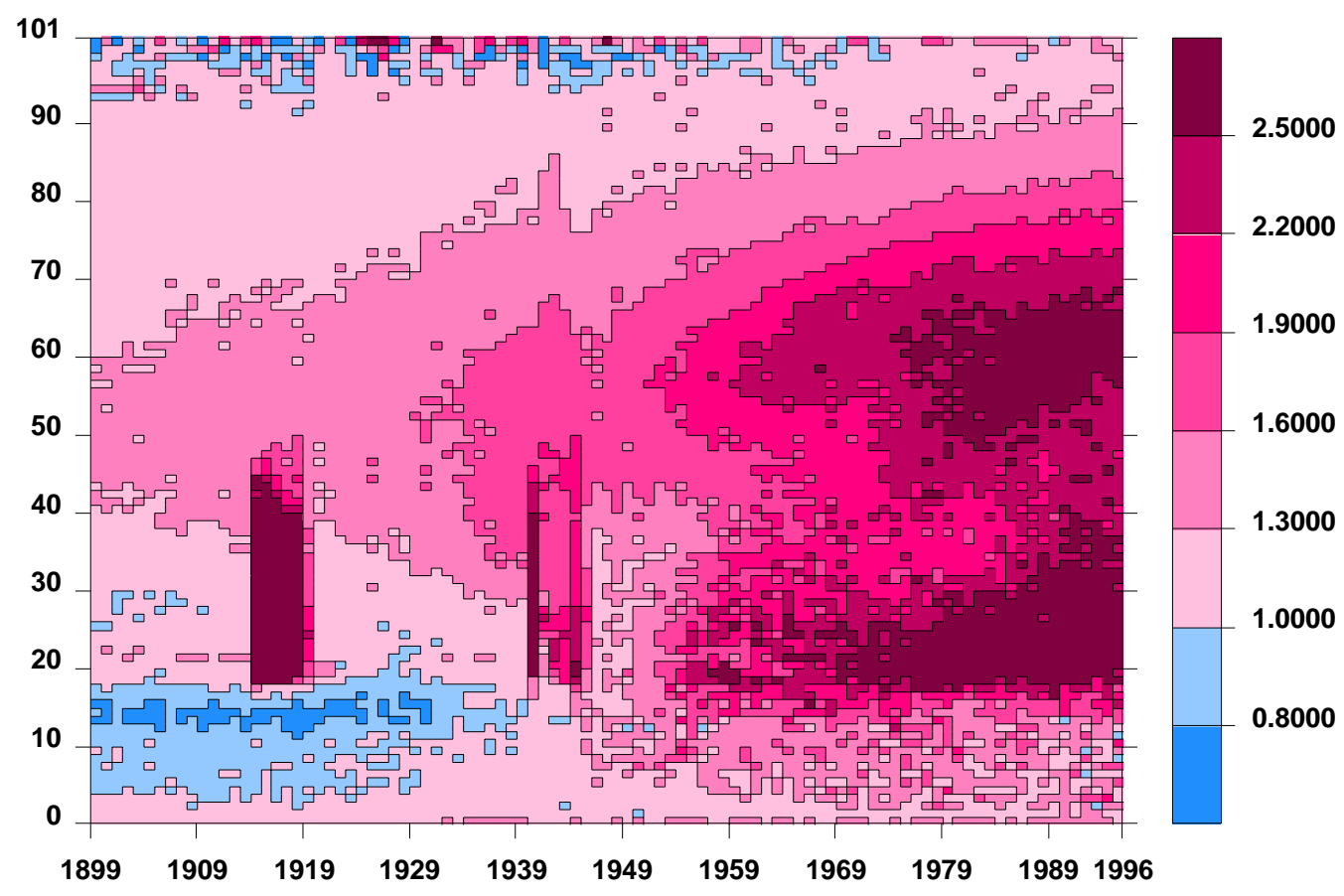

Source: The Berkeley Mortality Database 1997, http://demog.berkeley.edu/wilmoth/mortality b. Denmark

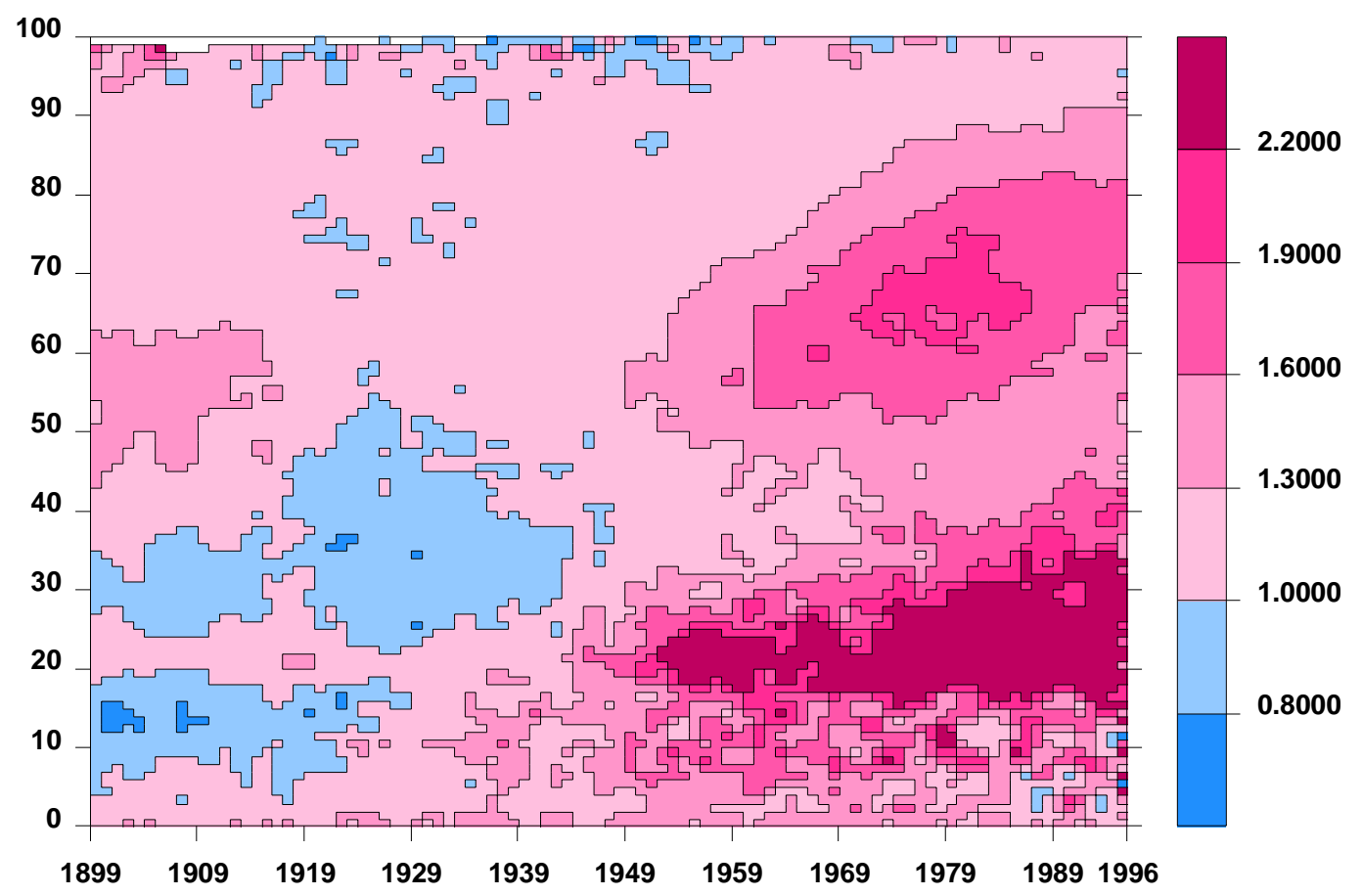

Source: K. Andreev 1999, PhD Thesis, Odense University (Unpublished). 